\title{
Cardiovascular magnetic resonance in carotid atherosclerotic
} disease

\author{
Li Dong1, William S Kerwin ${ }^{1}$, Marina S Ferguson ${ }^{1}$, Rui Li1 ${ }^{1}$, Jinnan Wang², \\ Huijun Chen ${ }^{1}$, Gador Canton ${ }^{1}$, Thomas S Hatsukami ${ }^{3}$ and Chun Yuan*1
}

\begin{abstract}
Address: ${ }^{1}$ Department of Radiology, University of Washington, Seattle, WA, USA, ${ }^{2}$ Clinical Sites Research Program, Philips Research North America, Briarcliff Manor, NY, USA and ${ }^{3}$ Department of Surgery, University of Washington, Seattle, WA, USA

Email: Li Dong - lido2@u.washington.edu; William S Kerwin - bkerwin@u.washington.edu; Marina S Ferguson - msf2@u.washington.edu; Rui Li - leerui@u.washington.edu; Jinnan Wang - jinnan.wang@philips.com; Huijun Chen - chenhj@u.washington.edu;

Gador Canton - gcanton@u.washington.edu; Thomas S Hatsukami - tomhat@u.washington.edu; Chun Yuan* - cyuan@u.washington.edu

* Corresponding author
\end{abstract}

Published: 15 December 2009

Journal of Cardiovascular Magnetic Resonance 2009, II:53 doi:10.1 186/1532-429X-I I-53

This article is available from: http://www.jcmr-online.com/content/ I I/I/53

(c) 2009 Dong et al; licensee BioMed Central Ltd.

This is an Open Access article distributed under the terms of the Creative Commons Attribution License (http://creativecommons.org/licenses/by/2.0), which permits unrestricted use, distribution, and reproduction in any medium, provided the original work is properly cited.
Received: 30 October 2009

Accepted: 15 December 2009

\begin{abstract}
Atherosclerosis is a chronic, progressive, inflammatory disease affecting many vascular beds. Disease progression leads to acute cardiovascular events such as myocardial infarction, stroke and death. The diseased carotid alone is responsible for one third of the 700,000 new or recurrent strokes occurring yearly in the United States. Imaging plays an important role in the management of atherosclerosis, and cardiovascular magnetic resonance (CMR) of the carotid vessel wall is one promising modality in the evaluation of patients with carotid atherosclerotic disease. Advances in carotid vessel wall CMR allow comprehensive assessment of morphology inside the wall, contributing substantial disease-specific information beyond luminal stenosis. Although carotid vessel wall CMR has not been widely used to screen for carotid atherosclerotic disease, many trials support its potential for this indication. This review summarizes the current state of knowledge regarding carotid vessel wall CMR and its potential clinical application for management of carotid atherosclerotic disease.
\end{abstract}

\section{Introduction}

The common carotid artery bifurcation is a zone of frequent atherosclerotic disease owing to the disturbed hemodynamics in the carotid bulb. Estimates place carotid atherosclerosis as the embolic source behind up to $30 \%$ of the 700,000 new or recurrent strokes annually in the United States [1]. With 5.8 million stroke survivors in the U.S., stroke is the leading cause of long-term disability and results in direct and indirect costs of $\$ 68.9$ billion per year [2]. As a common source of stroke, carotid atherosclerosis contributes substantially to the overall healthcare burden and costs both in the U.S. and worldwide.
To assess the risk of stroke from carotid atherosclerotic disease, the current standard is to measure the severity of luminal stenosis by angiography. Both the European Carotid Surgery Trial (ECST) and the North American Symptomatic Carotid Endarterectomy Trial (NASCET) showed that individuals with prior ischemic symptoms and carotid stenosis in excess of 50\% were at very high risk of stroke and that the risk was significantly reduced by surgery $[3,4]$. In asymptomatic individuals, studies are more equivocal and the benefit of surgery or screening for asymptomatic stenosis is hotly debated [5-8]. Notably, asymptomatic carotid stenosis in excess of $50 \%$ is very 
common with prevalence estimated at $12.5 \%$ in men and $6.9 \%$ in women over age 70 [9].

Furthermore, patients with high-grade stenosis likely represent just a fraction of those at risk of stoke due to carotid atherosclerosis. Given the unique geometry of the carotid bulb, which generally is larger in diameter than the more distal internal carotid, it is possible to have a minimal stenosis despite the presence of significant plaque burden. Furthermore, luminal stenosis measurement may underestimate plaque burden because of compensatory, expansive arterial remodeling, as originally described by Glagov [10]. Consequently, large advanced plaques are commonly observed in carotid arteries without measurable stenosis [11] and have been implicated in thromboembolic complications [12].

Given the uncertainty in patient management for highgrade asymptomatic stensosis and the failure of stenosis to characterize risk from lesions that do not compromise the lumen, better strategies for risk assessment are needed. Cardiovascular magnetic resonance (CMR) of the carotid vessel wall provides a new imaging approach with potential to identify the characteristics of the carotid atherosclerotic lesion itself. Carotid vessel wall CMR uses a combination of bright-blood and black-blood techniques to provide information regarding the structure of the carotid artery and the composition of the atherosclerotic plaque. These structural and compositional features are thought to play the central role in determining the risk posed by a carotid lesion. Thus, carotid vessel wall CMR may be the much needed tool for determining risk above and beyond stenosis.

The potential for direct and indirect clinical impact of carotid vessel wall CMR is not, however, limited to nearterm stroke prediction. The ideal therapeutic approach would prevent the high-risk lesion from ever developing. In this regard, carotid CMR has the potential to evaluate the performance of therapies in clinical trials, and to identify new targets for therapy to prevent progression toward high-risk lesions. Carotid CMR may also play a role in selecting and monitoring optimal therapy for specific lesion characteristics. Finally, the carotid artery can be used as a systemic marker of overall cardiovascular health to be assessed by carotid CMR.

To understand the many roles that carotid CMR can play in clinical management of carotid atherosclerosis, this review describes the near-term feasibility and capability of carotid vessel wall CMR. By considering how carotid atherosclerotic tissues appear on CMR, image interpretation criteria are provided for the key targets. We examine the carotid atherosclerotic plaque in various stages from the already disrupted plaque back to the early stage of plaque formation to see how CMR can play a role in each stage. The direct and potential clinical impacts of carotid vessel wall CMR are addressed.

\section{Feasibility of Clinical Carotid vessel wall CMR}

The attractiveness of CMR for assessment of the carotid artery wall derives from several factors. From a general imaging perspective, the carotid artery has beneficial physiology given its relatively large size, superficial location and remoteness from heart and lung motion. Phasedarray surface coils designed for carotid artery provide sufficient signal-to-noise ratio (SNR) for the high-resolution imaging required for characterizing plaque composition $[13,14]$. CMR itself comes with the standard benefits of being non-invasive and avoiding the use of ionizing radiation, which is particularly important for serial imaging studies.

The foremost advantage of CMR for this application is the ability to combine information from multiple contrast weightings. Through early investigations, a standardized carotid vessel wall CMR protocol emerged consisting of black-blood fast spin echo sequences including T1weighted (T1W), T2-weighted (T2W), and proton density weighted (PDW) imaging with fat suppression, combined with a bright-blood time of flight (TOF) sequence [15]. More recently, highly T1-weighted gradient echo sequences such as Magnetization-Prepared Rapid Acquisition Gradient-Echo (MP-RAGE) have been incorporated into carotid protocols [16]. Furthermore, these techniques can be augmented with injected contrast agents that provide improved or complementary information regarding plaque composition [17-19].

The availability of carotid plaque specimens from carotid endarterectomy has enabled the contrast features of plaque components to be validated and described in detail [20]. These studies have utilized serial histological cross sections with specialized staining to compare with the contrast features in corresponding cross-sectional CMR images acquired in vivo. Characteristics of common plaque components on CMR are summarized in Table 1. The optimal combination of contrast weightings depends on the imaging target(s) and will be discussed at length in the subsequent sections of this review.

\section{Technical considerations}

Perhaps the greatest challenge for carotid wall CMR is the resolution to distinguish the internal plaque structure. Even in advanced disease, the vessel wall may only measure a few millimeters in thickness, with the potential existence of multiple substructures across that dimension. These structures also change shape rapidly in the longitudinal direction of the artery. Thus, 2D imaging approaches have had to contend with in-plane resolutions 
Table I: Carotid CMR Characteristics

\begin{tabular}{|c|c|c|c|c|c|}
\hline & TOF & TIW & T2W & PD & CE-TIW* \\
\hline Fibrous tissue & o & 0 & 0 & 0 & 0 \\
\hline Calcification & - & - & - & - & - \\
\hline Lipid-Rich Necrotic Core & ○ & o & - & $-/ 0$ & - \\
\hline Hemorrhage & + & + & $-1+$ & $-/+$ & - \\
\hline
\end{tabular}

Note: + indicates hyper-intense; o indicates iso-intense; - indicates hypo-intense

*Contrast enhanced TIW (CE-TIW): + indicates enhancement present; - indicates enhancement absent

of $0.6 \mathrm{~mm}$ or less and slice thickness of 2-3 $\mathrm{mm}$. Recently, $3 \mathrm{D}$ isotropic imaging approaches have been proposed with isotropic resolution up to $0.6 \mathrm{~mm} \mathrm{[21].} \mathrm{In} \mathrm{both} \mathrm{2D}$ and 3D approaches, this resolution pushes the SNR limits of the scanner, requiring long acquisition times. Minimizing patient motion during the scan with the use of comfortable head holders or motion-corrected scanning is critical. Also, because of SNR limitations, the use of parallel imaging to reduce scan time is not recommended.

The increasing availability of 3.0 Tesla field-strength scanners provides some SNR benefits for carotid vessel wall CMR. Compared to $1.5 \mathrm{~T}$ CMR, black-blood carotid artery MR images at 3.0 Tesla have been found to have 1.4-2.4 times increased carotid wall SNR and lumen/wall contrast-to-noise ratio [22-24]. The higher SNR can be traded for reduced scan time of up to about $40-50 \%$ [22].

The novel developments of coils, sequences, and scanner, taken together, are a driving force for carotid vessel wall CMR to obtain higher spatial resolution within a reasonable scanning time on a clinically available scanner.

\section{Image postprocessing}

The importance of quantification in evaluating plaque burden and composition suggests a role for image postprocessing techniques. Highly automated measurement techniques can reduce analysis time, reduce readerdependent bias, and improve measurement reproducibility. Several semi-automated imaging processing tools have been used to quantitative indices of plaque burden and composition [25-27]. Underhill et al. proposed a technique using active shape models to segment the vessel boundaries [28]. Utilizing morphologic information such as local wall thickness, Liu et al. proposed a flexible, multi-contrast plaque segmentation technique (Morphology-Enhanced Probabilistic Plaque Segmentation, MEPPS) that is suitable for measuring plaque composition in vivo [27]. Recently, Kerwin et al. described a plaque analysis software (The Computer-Aided System for Cardiovascular Disease Evaluation, CASCADE) to provide quantitative information regarding plaque burden and composition, which was highly similar to manual outlining but with considerably less analysis time [29].

\section{CMR appearance of Carotid Plaque} Disrupted plaque

For CMR, the most important clinical question to be answered for patients with established carotid lesions is whether the lesion poses a high, near-term risk for complications. Retrospective histological studies of carotid atherosclerotic lesions implicated in ischemic stroke and transient ischemic attacks have found those lesions to exhibit plaque disruption, most commonly fibrous cap rupture (Figure 1). Spagnoli et al. reported ipsilateral fibrous cap rupture was observed in $66.7 \%$ (64/96) of patients with major stroke, 23.1\% (21/91) of patients with transient ischemic attack, and only $13.4 \%(11 / 82)$ of patients without prior ischemic symptoms [30]. Similarly, Carr et al. found that cap rupture occurred more frequently in symptomatic patients (74\%) than in asymptomatic patients (32\%) [31]. Once an atherosclerotic plaque is disrupted, the thrombogenic contents and lipid core are exposed to platelets and coagulation factors in circulating blood, predisposing the patient to an acute thromboembolic event. The study by Spagnoli et al. found that an acute thrombus was associated with cap rupture in $90.1 \%$ (64/71) patients with stroke. The clinical significance of plaque disruption begs the question whether CMR can visualize cap rupture. Of note, fibrous cap rupture and thrombosis can also occur in the carotid artery without overt clinical symptoms. Prior sites of rupture and thrombus can act as further stimuli for thrombus development. Thus, identification of these features on carotid vessel wall CMR could be an important part of a risk reduction strategy of stroke.

To visualize plaque disruption and thrombus, blackblood CMR sequences (T1W, T2W or PD) permit a clear differentiation of both the lumen and outer wall boundaries by suppressing the signal from flowing blood. Plaque disruption can be identified by an ulceration of the plaque surface, the discontinuity of fibrous cap, and thrombus on the surface (Figure 2). In a histology-validated study of 26 patients scheduled for endarterectomy, Kampschulte et al. was able to detect luminal and juxtaluminal thrombus with an accuracy of $96 \%$, by using an in vivo multi-contrast approach that primarily identified hyper-intense signals on TOF and T1W images that appeared to have direct contact with the lumen [32]. Moody et al. also used a non 


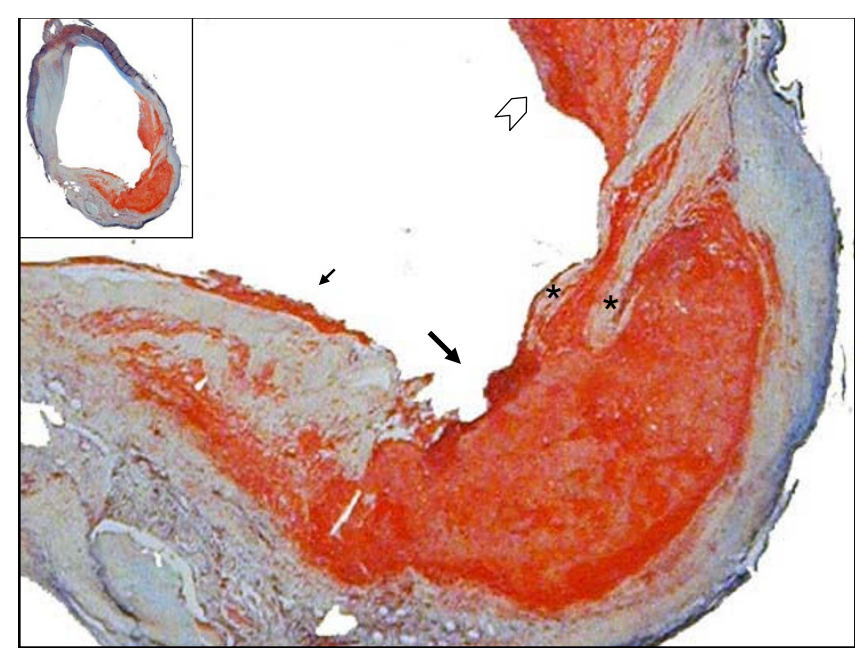

\section{Figure I}

The Ruptured Carotid Plaque. A Movat's Pentachrome stain of a common carotid fibrous cap disruption. The disruption (big arrow) is framed by two branches of the fibrous cap (asterisks) on the right side, and a cap overlaid with thrombus on the left (small arrow). The chevron points to a region of organizing thrombus. (Magnification 100x, inset 10x)

contrast-enhanced CMR method based on the T1-shortening properties of methemoglobin combined with a highly T1-weighted gradient echo protocol ("direct thrombus imaging") to identify hyper-intense regions of thrombus in the carotid artery [33].

In addition, black-blood sequences combined with bright-blood imaging techniques (3-dimensional TOF) can distinguish intact thick cap from intact thin and disrupted cap based on the lumen surface condition and the presence of a dark band along the lumen surface in TOF images [34]. The addition of gadolinium contrast agents, which lead to increase fibrous cap signal on T1W images, further aids in reliable assessment of fibrous cap status. A multi-contrast weighted CMR study including contrast enhanced images by kwee et al., found good intra- and inter-reader agreement $(k=0.96$ for intra-reader; $k=0.64$ for inter-reader) for fibrous cap status [35].

\section{Thin Fibrous Cap and Lipid-Rich Necrotic Core (LRNC)}

While detection of prior plaque rupture has clinical implications, a more compelling question is whether detectable precursors of cap rupture exist. The concept of the disruption-prone or high-risk/vulnerable plaque, initially derived from coronary studies, has been increasingly shown to apply in the carotid circulation. Histological studies have shown that the most common feature of plaques prone to rupture is a thin fibrous cap with a large underlying necrotic core (Figure 3) [36-39]. These features are key targets of carotid vessel wall CMR and are potential imaging markers for risk of stroke/transient ischemic attack.

The well established results in the visualization of lipidrich necrotic core (LRNC) have come from the use of black blood multi-contrast images (T1W, PDW, and T2W) using criteria that compares the signal intensity of the adjacent sternocleidomastoid muscle to the signal intensities of the black blood sequences [40-42]. The LRNC is a mixture of lipid, cellular debris, blood and water in various concentrations therefore MR signal intensities of the different sequences reflect those variations. In general, the LRNC appears isointense on T1W and TOF images, and hypointense on T2W images. An ex vivo carotid CMR study by Fabiano et al. using these criteria found the sensitivity and specificity for identifying the lipid core according to these criteria were $92 \%$ and $74 \%$ respectively [43]. A quatitative in vivo study by Saam et al. produced a $92 \%$ of sensitivity and $65 \%$ for specificity comparing the size of the lipid rich necrotic core to corresponding histology [44].

Gadolinium-based contrast agents provided additional information for characterization of the necrotic core and the fibrous cap (Figure 4) $[17,18,45]$. The addition of contrast agent can increase the signal intensity of fibrous tissue by $79.5 \%$ due to the presence of microvasculature; conversely, due to the lack of microvasculature, the necrotic core has the least enhancement 28.6\% [17]. The minimal enhancement of the LRNC results in good contrast with fibrous tissue and can be used to determine the boundary of the necrotic core with good accuracy as shown in Figure 4. Wasserman et al. found that gadolinium-enhanced $\mathrm{T} 1 \mathrm{~W}$ images could delineate the fibrous cap from the LRNC, with a contrast-to-noise ratio similar or better than that of T2W images but with approximately twice the signal-noise-ratio [18]. Takaya et al. also found that in vivo CMR measurement of LRNC size was more reproducible when using contrast agent [46]. Cai et al. took contrast one-step further by comparing the size of the enhanced fibrous cap to corresponding histology (For maximal thickness: $\mathrm{r}=0.78, p<0.001$; for length: $\mathrm{r}=0.73$, $p<0.001$; for area: $r=0.73, p<0.001$ ) [45].

\section{Intraplaque hemorrhage}

Intraplaque hemorrhage is thought to originate primarily from immature neovessels within the plaque that are prone to leakage [47]. The role of intraplaque hemorrhage in plaque development and rupture is not fully understood, but is currently believed to be a driving force in plaque progression through lipid accumulation from red blood cells [48]. It has also been implicated as a risk factor for plaque disruption, although previous studies testing its association with symptoms have varied results $[32,49,50]$. 


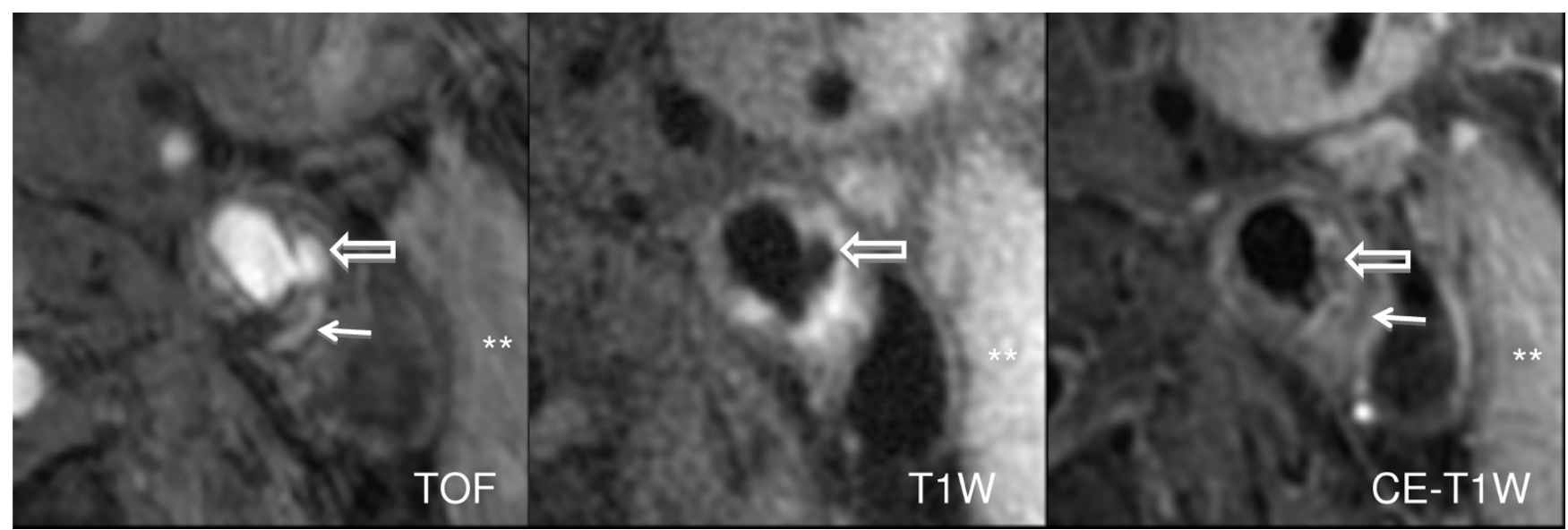

Figure 2

Magnetic Resonance Images of the Ruptured Carotid Plaque. The bright-blood 3D TOF image shows a distinct disruption of the fibrous cap (block arrow), corresponding to the hypointense juxtaluminal region on TIW and CE-TIW images. The hyperintense signal present in the necrotic core adjacent to the rupture (arrow) indicates presence of intraplaque hemorrhage inside of a lipid-rich necrotic core (thin arrow on CE-TIW image). Asterisks are placed on the sternocleidomastoid muscle, which is used to determine plaque signal intensities. The scan was acquired on a 3.0-T GE Signa Excite along with the use of a 4-element phased-array carotid coil.

Intraplaque hemorrhage (Figure 5) is most reliably detected by CMR in the methemoglobin stage due to short $\mathrm{T} 1$ relaxation time leading to hyper-intense signal on $\mathrm{T} 1 \mathrm{~W}$ images. In 2004 Chu et al. used a combined black blood T1 weighted turbo spin echo (TSE) sequence and a time of flight (TOF) sequence for hemorrhage detection. Hemorrhage was identified by hyper-intense signal intensity on both the TOF and T1W images. A T2W black blood TSE sequence was used to stage the early (hypo-intense on $\mathrm{T} 2 \mathrm{~W}$ images) or later phase (iso- or hyper-intense o) of the methemoglobin phase. Validation with corresponding histology showed that the technique had a sensitivity of $0.85-0.95$ and specificity of $0.7-0.77$ [51]. Moody et al. proposed another approach to the identification of intraplaque hemorrhage by using a heavily $\mathrm{T} 1$ weighted sequence 3D MP-RAGE (Magnetization-Prepared Rapid Acquisition Gradient-Echo) [16,52]. This technique takes advantage of the short $\mathrm{T} 1$ relaxation time of methemoglobin and produces a very bright signal. The technique has a reported sensitivity and specificity of $84 \%$ and $84 \%$ [52]. The limitation of MP-RAGE is that by using only the T1 shortening effect of methemoglobin, it cannot be used to differentiate the various stages of intraplaque hemorrhage.

\section{Calcification}

Calcification is commonly found in atherosclerosis and occurs both in areas that are viable and necrotic. Since the role of calcium deposition and its contribution to plaque stability is not well understood, there is a debate as to the extent to which plaque calcification contributes to plaque stability. Some studies demonstrated that the presence and extent of calcification may be associated with increased risk of plaque rupture [53-57], whereas others suggested that it has beneficial effects in stabilizing the plaque, making it stiffer and less prone to rupture [58-60]. There is current growing interest in the location of calcium, which may affect plaque vulnerability. Using a biomechanical model, $\mathrm{Li}$ et al. showed that predicted maximum stress was increased by $47.5 \%$ when calcium deposits were located in the thin fibrous cap. While the presence of calcium deposits in the lipid core or remote from the fibrous cap resulted in no increase in maximum stress $[61,62]$. It was conjectured that the presence of calcification within the lipid core may even stabilize the plaque by adding bulk [61]

MR imaging is able to detect plaque calcification with good sensitivity and specificity. Calcification (Figure 6) produces a hypo-intense signal on all contrast weightings due to low water content $[63,64]$. An 1.5 T CMR investigation by Fabiano et al. demonstrated that CMR has high sensitivity (98\%) and specificity (99\%) for the identifying plaque calcification [43]. Furthermore, Saam et al. reported a strong correlation between CMR and corresponding histology calcification area measurements $(\mathrm{r}=$ 0.74, $p<0.001$ ) [44]. At higher field strengths, the increased susceptibility of calcification may alter quantification and/or detection. Underhill et al. compared the quantification of carotid calcification at $1.5 \mathrm{~T}$ with those at $3.0 \mathrm{~T}$ magnetic resonance imaging, and found that the measurement of calcification was significantly larger at 


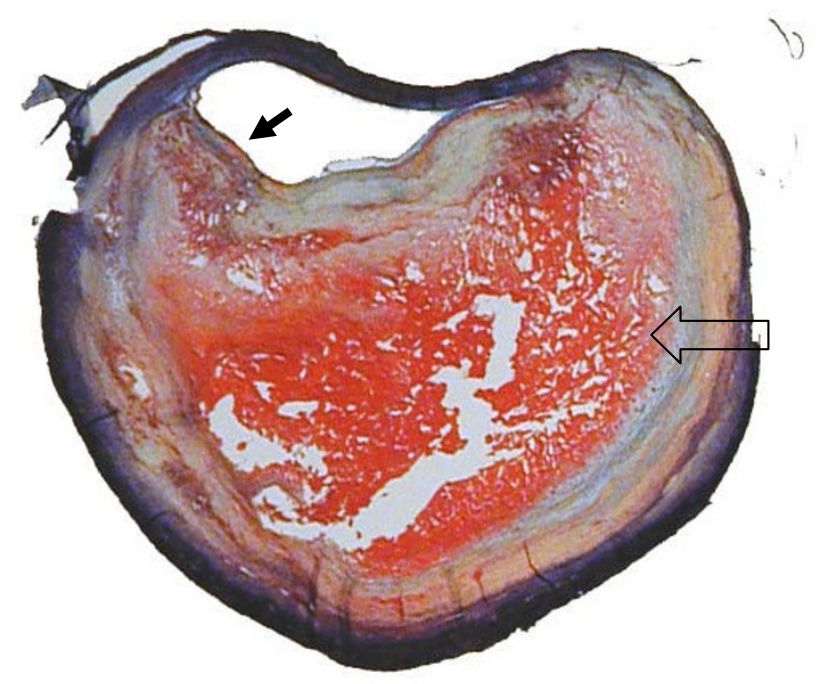

Figure 3

The rupture prone atherosclerotic plaque has a thin fibrous cap overlaying a large necrotic core. This Movat's Pentachrome stain shows a carotid plaque with a large necrotic core (block arrow) containing hemorrhage (red staining). The fibrous cap shows a dramatic thinning near the shoulder of the core (arrow in the lumen). (Magnification 10x)

$3.0 \mathrm{~T}$ (mean area of $7.9 \mathrm{~mm}^{2}$ vs. $5.9 \mathrm{~mm}^{2}, p=0.03$ ), but a high intraclass correlation of 0.79 was maintained [64].

\section{Inflammation}

Inflammation is the process by which the body responds to injury. In atherosclerotic disease the injury is the accumulation of lipids in the artery wall. As the lesion evolves proinflammaotry cytokines are expressed. These cytokines initiate a cascade that trigger endothelial cells to express adhesion molecules which then allow for the attachment of blood leucocytes [65]. The infiltration of inflammatory cells into the wall is the hallmark of early atherosclerotic disease and has been implicated in plaque rupture of advanced disease [66]. In the progression of carotid atherosclerosis, inflammation is characterized by increased endothelial permeability, macrophage infiltration, hypoxia within the vessel wall, and growth of the adventitial vasa vasorum. The recruited macrophages consume lipids, undergo apoptosis and thereby contribute to the development and growth of the necrotic core [66].

Within the atherosclerotic plaque, the distribution of inflammation is also associated with plaque stability (Figure 7). Inflammation is prevalent on the edges of the necrotic core and most importantly in the fibrous cap covering the core [67-71]. As inflammation progresses microvessels are recruited to supply the burgeoning population of cells. Moreno et al. found that microvessel density not only increased with inflammation but also correlated with plaque rupture [72]. Mofidi et al. found a significant association of increased microvasculature and with intraplaque hemorrhage, unstable atherosclerotic lesions and lesions obtained from symptomatic patients [73].

Based on the importance of plaque inflammation in determining the risk of progression or rupture considerable interest exists in the detection of vessel wall inflammation and its precursors. One CMR technique for assessing inflammatory burden in atherosclerosis is dynamic contrast enhanced CMR (DCE-CMR) with kinetic analysis of the contrast agents uptake. DCE-CMR methods, which use clinically available contrast agent, are widely used in cancer studies to assess tissue microvascularity and permeability [74]. In atherosclerotic plaque, microvessels, particularly those with high permeability, are thought to be the primary route for inflammatory cell infiltrate. These vessels also support existing macrophage metabolism. Thus, using kinetic modeling [75], the DCE-CMR parameters describing tissue microvascularity and permeability are considered to be markers of inflammation $[76,77]$.

A parameter of kinetic modeling derived from the DCECMR, fractional plasma volume $\left(\mathrm{v}_{\mathrm{p}}\right)$, is associated with a histological assessment of actual microvessel area. A correlation of 0.80 between $\mathrm{v}_{\mathrm{p}}$ measurements and the fractional area of microvessels determined from histology sections was found in 16 patients undergoing CEA, indicating that $\mathrm{v}_{\mathrm{p}}$ was an effective marker of plaque microvasculature [78]. Another parameter of kinetic modeling, the transfer constant (Krans) of the contrast agent, estimates the permeability of microvessels. In 27 patients, with analyzable CMR images and corresponding histology obtained from CEA, measurements of Ktrans were found to correlate with macrophage $(\mathrm{r}=0.75, p<0.001)$ and microvessel $(r=0.71, p<0.001)$ content [76]. A recent study by Kerwin et al. has shown that $\mathrm{K}^{\text {trans }}$ measurements of the adventitial region of the carotid were significantly correlated with serum markers of inflammation, such as C-reactive protein levels $(r=0.57 ; p=0.01)$ [77]. Figure 8 illustrates the steps necessary to calculate the $\mathrm{v}_{\mathrm{p}}$ and $\mathrm{K}^{\text {trans, }}$ which are represented by red $\left(\mathrm{v}_{\mathrm{p}}\right)$ and green ( $\left.\mathrm{K}^{\text {trans }}\right)$ channel in vasa vasorum imaging ( $\mathrm{V}-\mathrm{V}$ image).

DCE-CMR comes with several further advantages. DCECMR is easily integrated into existing CMR techniques for vessel wall characterization; it is a short procedure lasting minutes; it utilizes clinically available contrast agents that are safe in people with normal renal function; and the kinetic parameters can be measured with sub-millimeter resolution.

Another contrast-enhanced CMR technique using Ultrasmall Super-Paramagnetic Iron Oxide (USPIO) has been shown to identify carotid inflammatory burden in human 


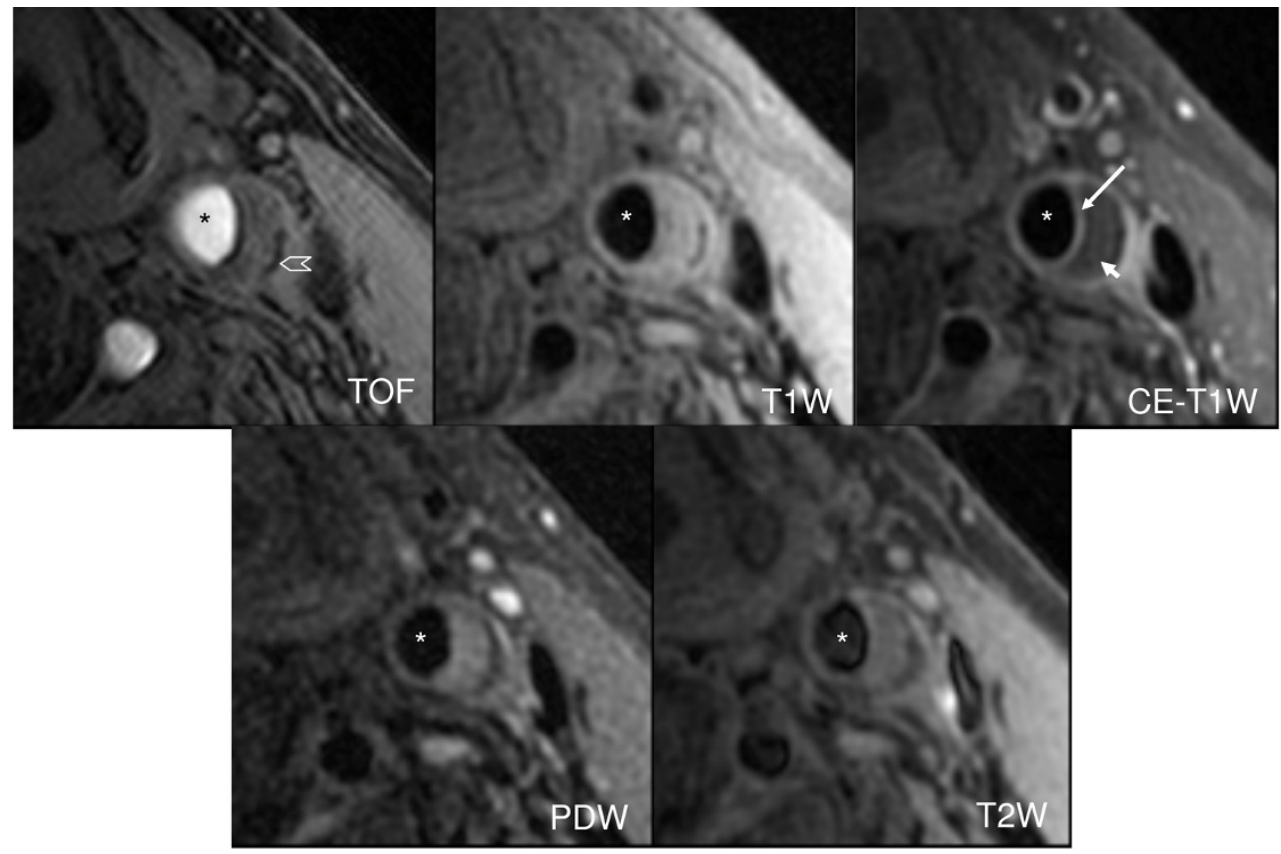

\section{Figure 4}

Atherosclerotic Carotid Artery Lipid-rich Necrotic Core. Multi contrast black and bright blood sequences show a large lipid-rich necrotic core (small arrow) with an intact thick fibrous cap best seen in the post contrast TI weighted (CE TIW) image (long arrow). Calcification is also visible at the base of the plaque (chevron). Asterisks are placed on the lumen.

studies in vivo $[79,80]$. USPIO particles, which enter atherosclerotic plaques with increased endothelial permeability and accumulate in macrophages, are visualized as a signal dropout or voids on CMR [81]. The accumulation of USPIOs in macrophages is a slow process so that the voids must be identified by comparing images obtained before and, ideally, 36-48 hours after injection [82]. Areas of focal signal loss on CMR images have been shown to correspond to accumulation of macrophage infiltration [83]. In a histological study, Trivedi et al. showed macrophages visualized by USPIO were present in 75\% (27/36) of the ruptured or rupture-prone plaques and $7 \%(1 / 14)$ of the stable athermatous lesions [79].

\section{Plaque Burden}

In addition to the assessment of plaque composition, disruption, and biology, black-blood CMR also permits simple measurements of wall thickness, area, and volume. These measurements are commonly grouped under the name "plaque burden." Measurements of plaque burden may be of particular importance in assessing the early formation of atherosclerotic plaque. It has been conjectured that the initiation of the atherosclerotic lesion begins when low-density lipoprotein (LDL) cholesterol molecules penetrate the arterial wall $[37,84,85]$. The lipids are taken up by macrophages and become fatty streaks. Due to the normal reactive response to injury (lipids), the arterial wall thickens. Thus, early disease is most readily deter- mined by wall thickness. Historically, the measurement of arterial wall thickness has been performed by $\mathrm{B}$ mode ultrasound (B-mode US) as the degree of intima-media thickness (IMT) in the carotid artery. Several studies have been shown that carotid vessel wall CMR can measure arterial wall accurately [86] and reproducibly on multiple scanner platforms [87], between scans and between readers [88-90]. In addition, measurements of the wall thickness by carotid vessel wall CMR have a high correlation with the IMT by B-mode US. Underhill et al. found that a high correlation between measurements of wall thickness on B-mode US and CMR $(r=0.93, p<0.001)$ [91]. Thus carotid vessel wall CMR is well poised for use in studies of early carotid atherosclerosis.

\section{Clinical roles for carotid vessel wall CMR \\ Retrospective Risk}

To establish the potential for carotid CMR to be used in the assessment of stroke risk, numerous studies have retrospectively investigated the relationship between prior ischemic strokes or transient ischemic attacks and the presence of disrupted plaque. In 23 unilateral symptomatic patients with $>50 \%$ stenosis on the symptomatic side, Saam et al. showed an association between symptoms and ruptured plaques when compared to the asymptomatic plaques (78\% vs. $30 \%, p=0.007$ ) [92]. They also found that symptomatic plaques were associated with a higher occurrence of thrombus (61\% vs. $26 \%, p=0.039$ ) 

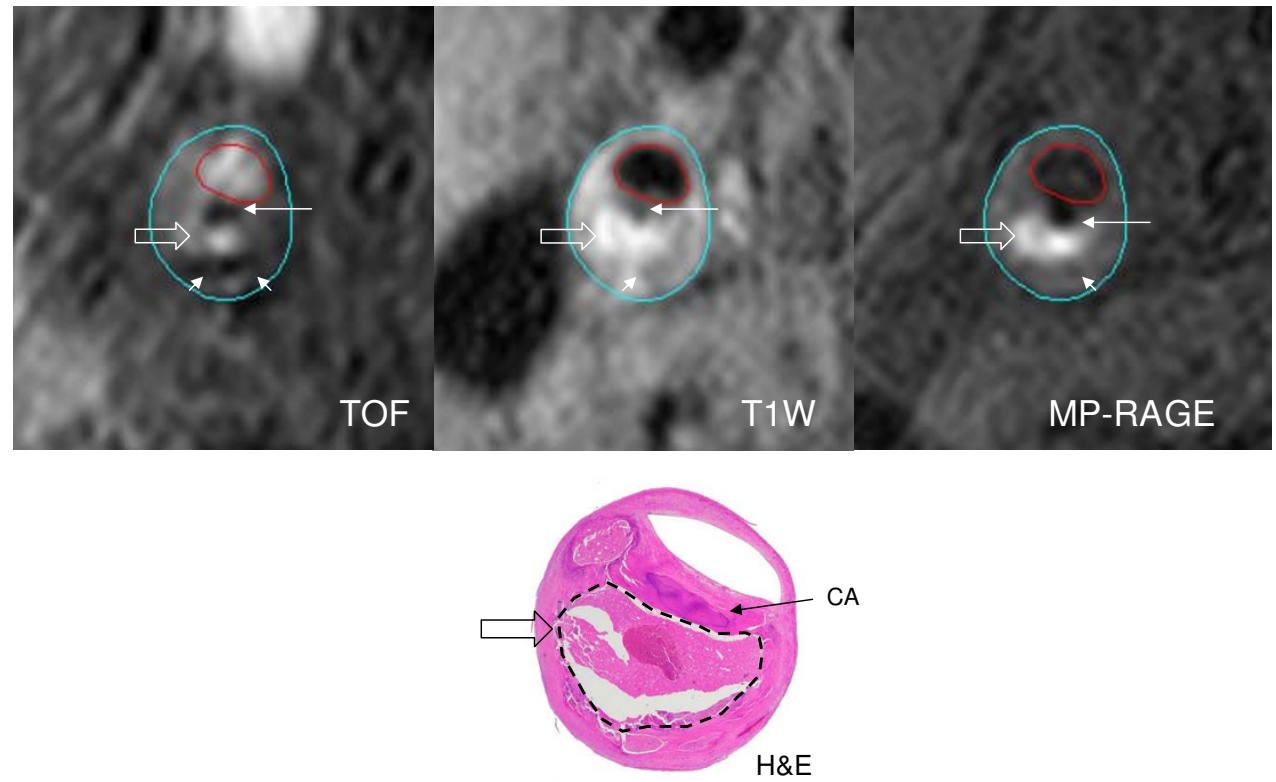

\section{Figure 5}

MR bright-blood sequence Time of Flight (TOF), and black-blood sequences TIW, and MPRAGE show a hyperintense signal (white block arrows) in the necrotic core. Hematoxylin and Eosin (H\&E) stained matching histology shows a large necrotic core (broken lines) filled with hemorrhage. The hypointense signal (thin arrow) in the fibrous cap is shown by matching histology to be an area of calcification.

[92]. Sadat et al. discovered the utility of multi-contrast CMR while looking at carotid plaques of 60 patients, fibrous cap rupture was observed in $50 \%$ of the acute symptomatic patients, $35 \%$ of recently symptomatic patients and no fibrous cap rupture was found in asymptomatic patients [93]. Yuan et al. found that patients with ruptured caps were 23 times more likely to have had a recent TIA or stroke, compared with patients with thick fibrous caps [94].

Additional studies have explored the relationship between other features of the carotid plaque and prior symptoms. Murphy et al. found that hemorrhage was occurred significantly more common in the patients' ipsilateral vessels compared with the contralateral, asymptomatic side ( $60 \%$ vs. $36 \%, p<0.001)$, and no hemorrhage was found in a gender and age matched healthy control group [95]. Howarth et al. also explored the degree of CMR defined inflammation using USPIO particles, between symptomatic and asymptomatic carotid plaques [96]. They found that symptomatic patients had more focal areas of signal drop than asymptomatic individuals ( $75 \%$ vs. $32 \%, p<0.01)$, thus suggesting that symptomatic plaques had large inflammatory infiltrates. Interestingly, asymptomatic individuals more frequently showed signal enhancement, which they attributed to low concentrations of USPIOs achieving positive contrast within thicker fibrous caps. Furthermore, they reported that some asymptomatic plaques also had focal areas of signal drop by using USPIOs, suggesting an occult macrophage burden [96].

\section{Prospective Risk}

A more compelling argument for carotid CMR risk assessment comes from its ability to prospectively associate CMR features of plaque with future development of symptoms. In a prospective study of 154 subjects with a mean follow-up period of 38 months, Takaya et al. showed that the presence of thin or disrupted fibrous cap, intraplaque hemorrhage, larger lipid-rich necrotic core or thicker wall was associated with an increased occurrence of subsequent neurological complications [97]. In a similar study, Altaf et al. found that intraplaque hemorrhage was a good predictor of ipsilateral stroke and TIA in 64 patients with symptomatic mild to moderate (30\%-69\%) carotid stenosis over 2 years (hazard ratio $=9.8, p=0.03$ ) [98].

\section{Plaque Natural History Studies}

CMR has also played a role in understanding what aspects of plaque morphology affect plaque progression and population differences in the disease. These factors may play a role in improved, patient-specific treatment of the disease. In an ethnicity-based study, Saam et al. investigated symptomatic carotid disease in Mainland Chinese patients and a comparable group of Caucasian Americans by using carotid vessel wall CMR [99]. They found signif- 


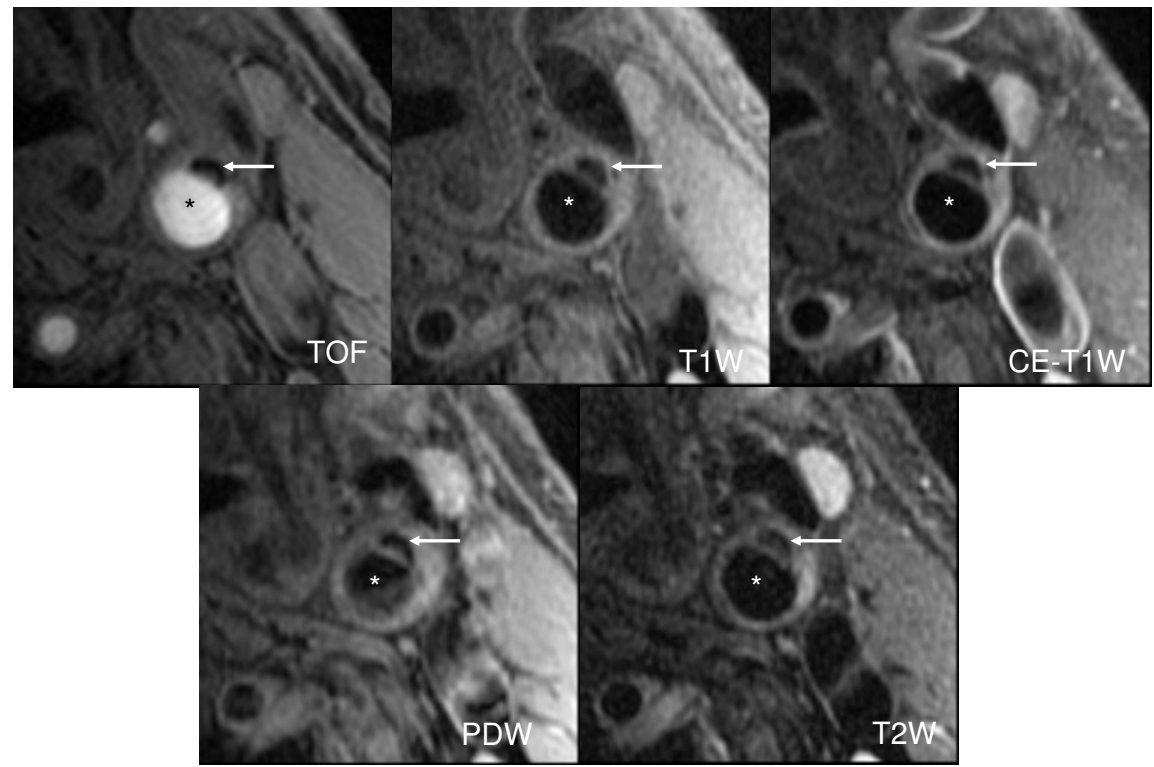

\section{Figure 6}

Calcification can be found in early atherosclerotic lesions. Black and bright blood multicontrast images show the presence of calcification in the wall of an early lesion of the left common carotid artery (arrow). Asterisks are placed on the lumen.

icant differences between the Chinese and Americans for the lipid-necrotic core (13.6 vs. $\left.7.8 \mathrm{~mm}^{2}, p=0.002\right)$. Also the wall area in the common carotid artery was larger in the Chinese population ( 52.5 vs. $\left.37.5 \mathrm{~mm}^{2}, p=0.007\right)$. In a natural history study, Takaya et al. found that repeated bleeding into the plaque may produce a stimulus for the progression of atherosclerosis by increasing lipid core and plaque volume and creating new destabilizing factors [97]. Hemorrhage into the carotid atherosclerotic plaque accelerated plaque progression in an 18-month period. The change in wall volume ( $6.8 \%$ vs. $-0.15 \%, p=0.009)$ and lipid-rich necrotic core volume (28.4\% vs. $-5.2 \%, p=$ 0.001 ) was significantly higher in the hemorrhage group than in controls over the course of the study. Furthermore, those with intraplaque hemorrhage at baseline were much more likely to have new plaque hemorrhages at 18 months compared with controls ( $43 \%$ vs. $0 \%, p=0.006)$. Besides plaque composition change, in another natural history study, Saam et al. identified factors that may alter the rate of progression in plaque burden [100]. On average, the wall area increased by $2.2 \%$ per year $(p=0.001)$. Findings from this study suggested that increased normalized wall index $(>0.64, p=0.001)$ and the use of statin therapy ( $p=0.01)$ were associated with reduced rates of plaque burden progression amongst asymptomatic patients $(\mathrm{n}=68)$ with advanced carotid atherosclerosis (stenosis $\geq 50 \%$ ) over an 18-month period.

\section{Pharmaceutical Trials}

The ability of carotid vessel wall CMR to characterize changes in plaque over time has had perhaps its greatest impact in the evaluation of treatment effect in clinical tri- als. Multiple, long-term, randomized studies have clearly proven that statin therapy reduces clinical events [101103]. Several prospective CMR investigations have demonstrated that statin therapy regresses carotid plaque burden by using CMR $[104,105]$. In addition, statin therapy has also been shown to specifically reduce the size of the LRNC [106]. Recently, Zhao et al. reported carotid CMR results from a randomized, double-blind clinical trial directed at assessing the lipid-depletion hypothesis [107]. They found in subjects with a LRNC $(\mathrm{n}=33)$, the LRNC on average decreased by $12 \mathrm{~mm}^{3}(\mathrm{p}=0.007)$ in $1^{\text {st }}$ year, by $13 \mathrm{~mm}^{3}(\mathrm{p}=0.004)$ in $2^{\text {nd }}$ year, and by $0.7 \mathrm{~mm}^{3}(\mathrm{p}=0.3)$ in $3^{\text {rd }}$ year [107]. In addition, in the ORION trial (4522IL/ 0044), Underhill et al. reported the similar effect of rosuvastatin on LRNC in the patients with moderate hypercholesterolemia, regardless of high-dose $(40 \mathrm{mg})$ or lowdose (5 mg) randomization [106] over the course of 2 years of treatment (\% LRNC: an overall reduction from baseline of $41.4 \% \pm 9.6 \%, p=0.005$ ). In a latter natural history study, Underhill et al. found that statin therapy in general was associated with a halting of plaque progression [108]. In this study, participants on statin therapy did not demonstrate any significant change in plaque burden after 18 months compared to the non-statin group that had a significant increase in plaque size [108]. Interestingly, this study also found that intraplaque hemorrhage may offset the effects of statin therapy [108]. The study suggested intraplaque hemorrhage mitigates the effects of statins, an approach beyond lipid lowering therapy may be necessary to counter the effects of intraplaque hemorrhage. 

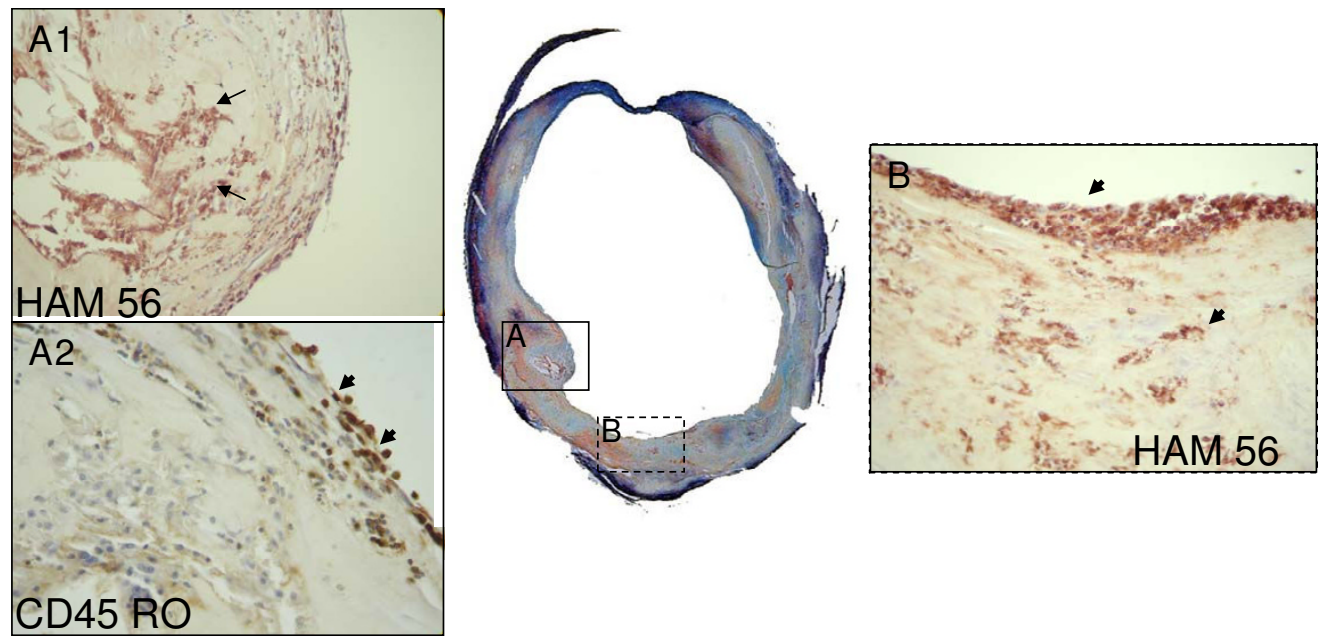

\section{Figure 7}

The Movat's Pentachrome stain of an atherosclerotic common carotid shows that a large lumen can mask complex inflammatorylesions. Inset AI shows a well developed core surrounded by macrophages stained brown with the macrophage marker HAM 56 (arrows). Inset A2 is a high power view of the same lesion stained with the antibody to CD45RO and shows activated $T$ cells on the lumen surface (short arrows). Inset B shows macrophages (brown) clustered on the lumen surface (short arrow) and throughout the neointima (short arrow) indicating plaque activity and progression. (Magnification I $0 \times$ for full figure and $400 \times$ for insets)

More recently, there were several CMR based studies to investigate the effects of statin therapy on macrophage activity in carotid atherosclerotic plaques. Carotid Plaque Composition (CPC) study is an ongoing study to investigate the effect of intensive lipid therapy on DCE-CMR defined inflammation [109]. After 1 year of treatment, a statistically significant reduction was found in DCE-CMR defined inflammation $\left(K^{\text {trans }}\right.$ from $0.085 \pm 0.037$ to 0.067 $\left.\pm 0.028 \mathrm{~min}^{-1}, p=0.02\right)$. ATHEROMA was a study undertaken to investigate the effects of low-dose $(10 \mathrm{mg})$ and high-dose ( $80 \mathrm{mg}$ ) atorvastatin on macrophage activity in carotid atherosclerotic plaques using serial USPIOenhanced CMR [110]. A significant reduction from baseline in USPIO-defined inflammation was observed in the $80-\mathrm{mg}$ group at both 6 weeks (signal intensity change $[\Delta \mathrm{SI}] 0.13, p=0.0003)$ and at 12 weeks $(\Delta$ SI $0.20, p<$ $0.0001)$. No difference was observed with the $10-\mathrm{mg}$ group. However, several drawbacks stand in the way of the widely clinical application of USPIO-enhanced CMR. One is that at least $2 \mathrm{CMR}$ scans are required before and after infusion of contrast medium. In addition, the calculation of percentage reduction in signal loss needs to be more reproducible since the signal reduction is dependent on reproducibility of coil positioning and on image coregistration before and after USPIO infusion.

\section{Systemic Risk}

A final area for carotid wall CMR that may be of clinical relevance is the potential to use the carotid artery as a marker of overall systemic disease. Individuals may go on to develop atherosclerosis due to the process of aging. A recent study by Keenan et al., imaged 100 healthy subjects (10 per sex per decade), and found that even in normal subjects the carotid wall volume increased with age [111]. The increase in wall volume correlates negatively with wall distensibility giving rise to a combination of age and pre clinical atherosclerosis related changes. These results are important for further carotid MR studies of early atherosclerosis.

The thickness of carotid arterial wall has correlated well with increased risk factors for atherosclerosis, and the likelihood of future vascular events [112]. Mani et al. stated that a greater wall thickness is prevalent among patients with prior major cardiovascular or cerebrovascular events (MACE) [113]. In their study $(n=195)$, patients with aged 50 years or older and with at least two risk factors for atherosclerosis were recruited, they found that patients with prior MACE had significantly higher MR wall thickness in carotids and thoracic aorta compared to those without prior MACE (Wall thickness carotids: $1.03 \pm 0.03$ vs. $0.93 \pm 0.03, p=0.001$; wall thickness aorta: $1.63 \pm 0.10$ vs. $1.50 \pm 0.04, p=0.009$, respectively). CMR provides a new opportunity to investigate carotid disease as a systemic marker of overall cardiovascular health.

\section{Discussion}

In summary, carotid vessel wall CMR appears poised for use in clinical applications and is, in fact, having an indirect clinical impact today through clinical trials involving 


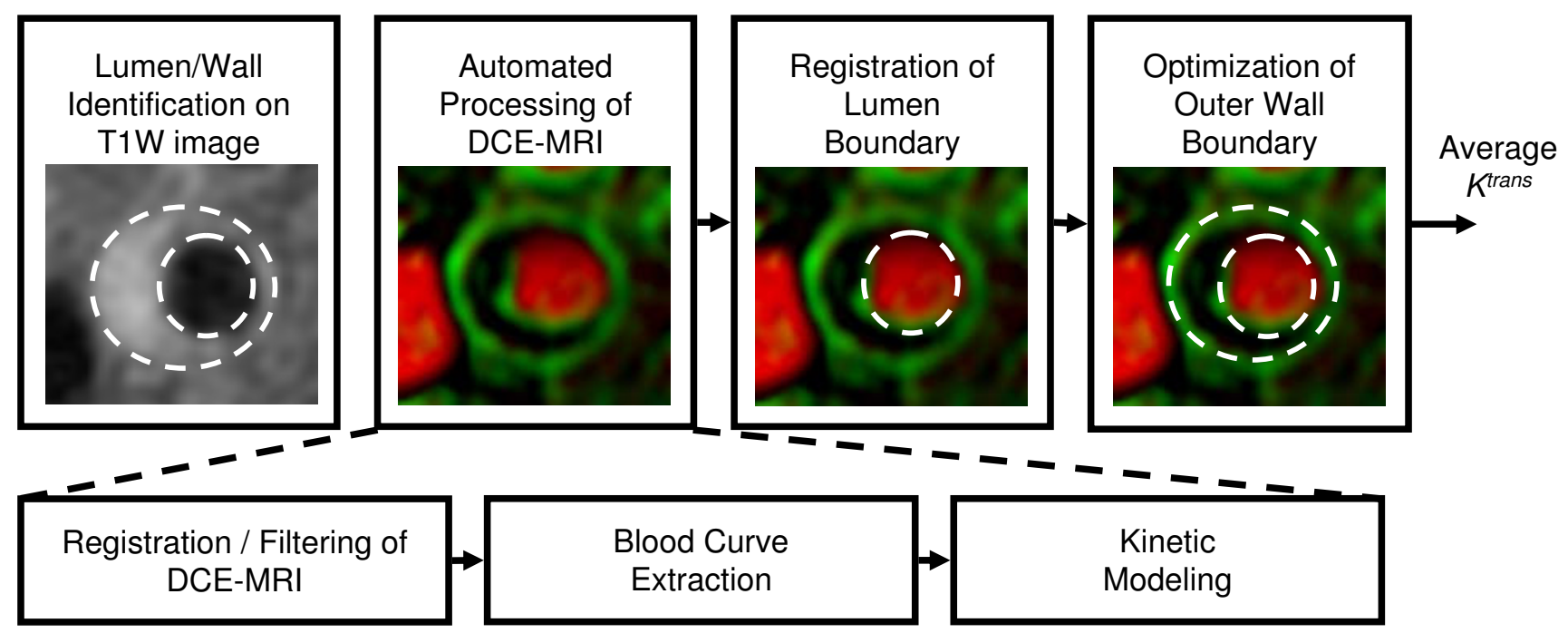

Figure 8

Contrast Enhanced MRI (DCE-MRI) with Kinetic Remodel. V-V image generated by the dynamic contrast enhanced MRI (DCE-MRI) with kinetic remodel. Illustration of the steps in creating a vasa vasorum image: boundaries drawn on a conventional contrast define a region of interest for processing. Within this region, DCE-MRI images are run through the KFRS algorithm, and then a blood curve (AIF) is automatically extracted and used for kinetic modeling. Finally, the boundaries are mapped to the resulting vasa vasorum image and Ktrans is measured in the wall. Reprinted, with permission from Ref [77].

carotid CMR. Numerous studies support the hypothesis that features of the carotid vessel wall identified with CMR can segregate individuals with similar degrees of stenosis into higher and lower risk categories. Thus, carotid vessel wall CMR is a promising candidate to be an additional diagnostic tool for management of patients with carotid atherosclerosis. The achievements of carotid vessel wall CMR to date strongly indicate the need for a large multicenter trial of its merits for patient management.

Additionally, CMR technology applicable to carotid vessel wall imaging is evolving rapidly. Within the next decade, considerable new techniques are expected to further refine our capabilities in charactering carotid atherosclerosis. Most notably, molecular imaging techniques are being developments for highly specific enhancement of components such as fibrin [114], angiogenic integrins [115], macrophage receptors [116], and lipid-rich areas [117]. Ultimate use of these technologies in human is, however, uncertain. In this review, we addressed only technologies that would be suitable for clinical use immediately if indicated.

Also, the vessel wall imaging capabilities of CMR are not limited to the carotid arteries. Imaging methods developed for carotid artery may be translated to other beds, although each one has to tailor to the local environment. Like carotid arteries, femoral arteries are relatively accessible to surface coils and benefit most from improvements in field-strength and surface coil design [118]. In contrast, owing to their size and complex anatomy, coronary and aortic images are impeded by various factors $[119,120]$. For example, motion compensation needs to be considered in coronary and aortic arteries. Image quality may be improved by using cardiac and respiratory gating. In addition, blood flow velocities and directions in different arterial beds should be considered as they determine blood suppression efficiency in most black-blood techniques.

In conclusion, CMR of the early and advanced atherosclerotic plaque has shown promise in providing understanding of the biology of the disease and a potential to provide clinical risk assessments for individual carotid atherosclerotic plaques. Multi-contrast CMR is currently in use in clinical trials to determine the effectiveness of new drugs and therapies. The capacity to non-invasively monitor the disease may lead to novel therapeutic targets that are associated with rapid progression or a muted response to conventional treatments. With the continual development of CMR techniques, vessel wall CMR is likely to be widely used for atherosclerosis management clinically in the near future.

\section{Competing interests}

This work was funded by the NIH grant RO1 HL56874, a grant from Pfizer, and an NIH-funded collaboration with VPDiagnostics, Inc. R44 HL070576.

\section{Authors' contributions}

LD, WK, MF, RL, JW, HC, GC, TH and CY drafted the manuscript. All authors read and approved the final manuscript. 


\section{References}

I. Chaer R, DeRubertis B, Patel S, Lin S, Kent C, Faries P: Current management of extracranial carotid artery disease. Rev Recent Clin Trials 2006, I(3):293-30I.

2. Lloyd-Jones D, Adams R, Carnethon M, De Simone G, Ferguson T, Flegal K, Ford E, Furie K, Go A, Greenlund K, Haase N, Hailpern S, Ho M, Howard V, Kissela B, Kittner S, Lackland D, Lisabeth L, Marelli A, McDermott M, Meigs J, Mozaffarian D, Nichol G, O'Donnell C, Roger V, Rosamond W, Sacco R, Sorlie P, Stafford R, Steinberger J, Thom T, Wasserthiel-Smoller S, Wong N, Wylie-Rosett J, Hong Y: Heart disease and stroke statistics--2009 update: a report from the American Heart Association Statistics Committee and Stroke Statistics Subcommittee. Circulation 2009, I I 9(3):480-486.

3. Barnett H, Taylor D, Eliasziw M, Fox A, Ferguson G, Haynes R, Rankin R, Clagett G, Hachinski V, Sackett D, Thorpe K, Meldrum H, Spence $\mathrm{J}$ : Benefit of carotid endarterectomy in patients with symptomatic moderate or severe stenosis. North American Symptomatic Carotid Endarterectomy Trial Collaborators. N Engl J Med 1998, 339(20): |4I5-|425.

4. Rothwell P, Gutnikov S, Warlow C: Reanalysis of the final results of the European Carotid Surgery Trial. Stroke 2003, 34(2):514-523.

5. Rothwell P: Endarterectomy for symptomatic and asymptomatic carotid stenosis. Neurol Clin 2008, 26(4): 1079-1097.

6. Gates P, Chambers B, Yan B, Chong W, Denton M: Symptomatic and asymptomatic carotid stenosis: just when we thought we had all the answers. Intern Med J 2006, 36(7):445-45I.

7. Cardona P, Rubio F, Martinez-Yélamos S, Krupinski J: Endarterectomy, best medical treatment or both for stroke prevention in patients with asymptomatic carotid artery stenosis. Cerebrovasc Dis 2007, 24(Suppl I): I 26-133.

8. Redgrave J, Rothwell P: Asymptomatic carotid stenosis: what to do. Curr Opin Neurol 2007, 20( I):58-64.

9. de Weerd M, Greving J, de Jong A, Buskens E, Bots M: Prevalence of asymptomatic carotid artery stenosis according to age and sex: systematic review and metaregression analysis. Stroke 2009, 40(4): I I05-I I I3.

10. Glagov S, Weisenberg E, Zarins C, Stankunavicius R, Kolettis G: Compensatory enlargement of human atherosclerotic coronary arteries. $N$ Engl J Med I987, 3 I 6(22): I 37I-I375.

II. Dong L, Underhill H, Yu W, Ota H, Hatsukami T, Gao T, Zhang Z, Oikawa M, Zhao X, Yuan C: Geometric and Compositional Appearance of Atheroma in an Angiographically Normal Carotid Artery in Patients with Atherosclerosis. AJNR Am J Neuroradiol 2009 in press.

12. Trivedi R, U-King-Im J, Graves M, Gillard J, Kirkpatrick P: Non-stenotic ruptured atherosclerotic plaque causing thromboembolic stroke. Cerebrovasc Dis 2005, 20(I):53-55.

13. Hayes C, Mathis C, Yuan C: Surface coil phased arrays for highresolution imaging of the carotid arteries. J Magn Reson Imaging 6(I): $109-112$

14. Ouhlous M, Lethimonnier F, Dippel D, van Sambeek M, van Heerebeek L, Pattynama P, Lugt A van Der: Evaluation of a dedicated dual phased-array surface coil using a black-blood FSE sequence for high resolution MRI of the carotid vessel wall. Magn Reson Imaging 2002, I 5(3):344-35I.

15. Yuan C, Kerwin W, Yarnykh V, Cai J, Saam T, Chu B, Takaya N, Ferguson M, Underhill H, Xu D, Liu F, Hatsukami T: MRI of atherosclerosis in clinical trials. NMR Biomed 2006, I 9(6):636-654.

16. Zhu D, Ferguson M, DeMarco J: An optimized 3D inversion recovery prepared fast spoiled gradient recalled sequence for carotid plaque hemorrhage imaging at 3.0 T. Magn Reson Imaging 2008, 26( I 0): I 360-I366.

17. Yuan C, Kerwin WS, Ferguson MS, Polissar N, Zhang S, Cai J, Hatsukami TS: Contrast-enhanced high resolution MRI for atherosclerotic carotid artery tissue characterization. J Magn Reson Imaging 2002, I 5(I):62-67.

18. Wasserman BA, Smith WI, Trout HH, Cannon RO, Balaban RS, Arai $A E$ : Carotid artery atherosclerosis: in vivo morphologic characterization with gadolinium-enhanced double-oblique MR imaging initial results. Radiology 2002, 223(2):566-573.

19. Aoki S, Aoki K, Ohsawa S, Nakajima H, Kumagai H, Araki T: Dynamic MR imaging of the carotid wall. J Magn Reson Imaging 1999, 9(3):420-427.
20. Yuan C, Kerwin W: MRI of atherosclerosis. J Magn Reson Imaging 2004, 19(6):710-719.

21. Koktzoglou I, Li D: Submillimeter isotropic resolution carotid wall MRI with swallowing compensation: imaging results and semiautomated wall morphometry. J Magn Reson Imaging 2007, 25(4):8I5-823.

22. Yarnykh VL, Terashima $M$, Hayes CE, Shimakawa A, Takaya $N$, Nguyen PK, Brittain JH, McConnell MV, Yuan C: Multicontrast black-blood MRI of carotid arteries: comparison between I.5 and 3 tesla magnetic field strengths. J Magn Reson Imaging 2006, 23(5):691-698.

23. Anumula S, Song HK, Wright AC, Wehrli FW: High-resolution black-blood MRI of the carotid vessel wall using phased-array coils at I.5 and 3 Tesla. Acad Radiol 2005, I 2(I 2): I 52 I-I 526.

24. Koktzoglou I, Chung Y-C, Mani V, Carroll T], Morasch MD, Mizsei G, Simonetti OP, Fayad ZA, Li D: Multislice dark-blood carotid artery wall imaging: a I.5 T and 3.0 T comparison. J Magn Reson Imaging 2006, 23(5):699-705.

25. Yuan C, Lin E, Millard J, Hwang J: Closed contour edge detection of blood vessel lumen and outer wall boundaries in blackblood MR images. Magn Reson Imaging 1999, I 7(2):257-266.

26. Ladak HM, Thomas JB, Mitchell JR, Rutt BK, Steinman DA: A semiautomatic technique for measurement of arterial wall from black blood MRI. Med Phys 200 I, 28(6): I098-I 107.

27. Liu F, Xu D, Ferguson M, Chu B, Saam T, Takaya N, Hatsukami T, Yuan C, Kerwin W: Automated in vivo segmentation of carotid plaque MRI with Morphology-Enhanced probability maps. Magn Reson Med 2006, 55(3):659-668.

28. Underhill HR, Kerwin WS, Hatsukami TS, Yuan C: Automated measurement of mean wall thickness in the common carotid artery by MRI: a comparison to intima-media thickness by Bmode ultrasound. J Magn Reson Imaging 2006, 24(2):379-387.

29. Kerwin W, Xu D, Liu F, Saam T, Underhill H, Takaya N, Chu B, Hatsukami T, Yuan C: Magnetic resonance imaging of carotid atherosclerosis: plaque analysis. Top Magn Reson Imaging 2007, | 8(5):37|-378.

30. Spagnoli L, Mauriello A, Sangiorgi G, Fratoni S, Bonanno E, Schwartz R, Piepgras D, Pistolese R, Ippoliti A, Holmes DJ: Extracranial thrombotically active carotid plaque as a risk factor for ischemic stroke. JAMA 2004, 292( I 5): | 845- | 852

31. Carr S, Farb A, Pearce W, Virmani R, Yao J: Atherosclerotic plaque rupture in symptomatic carotid artery stenosis. J Vasc Surg 1996, 23(5):755-765. discussion 765-756.

32. Kampschulte A, Ferguson M, Kerwin W, Polissar N, Chu B, Saam T, Hatsukami T, Yuan C: Differentiation of intraplaque versus juxtaluminal hemorrhage/thrombus in advanced human carotid atherosclerotic lesions by in vivo magnetic resonance imaging. Circulation 2004, I I 0(20):3239-3244.

33. Moody A, Allder S, Lennox G, Gladman J, Fentem P: Direct magnetic resonance imaging of carotid artery thrombus in acute stroke. Lancet 1999, 353(9|47): I22-123.

34. Hatsukami T, Ross R, Polissar N, Yuan C: Visualization of fibrous cap thickness and rupture in human atherosclerotic carotid plaque in vivo with high-resolution magnetic resonance imaging. Circulation 2000, I 02(9):959-964.

35. Kwee R, van Engelshoven J, Mess W, ter Berg J, Schreuder F, Franke C, Korten A, Meems B, van Oostenbrugge R, Wildberger J, Kooi M: Reproducibility of fibrous cap status assessment of carotid artery plaques by contrast-enhanced MRI. Stroke 2009, 40(9):30I7-302I.

36. Virmani R, Kolodgie F, Burke A, Farb A, Schwartz S: Lessons from sudden coronary death: a comprehensive morphological classification scheme for atherosclerotic lesions. Arterioscler Thromb Vasc Biol 2000, 20(5): I262-1275.

37. Lusis AJ: Atherosclerosis. Nature 2000, 407(680 I):233-24I.

38. Naghavi M, Libby P, Falk E, Casscells SW, Litovsky S, Rumberger J, Badimon J], Stefanadis C, Moreno P, Pasterkamp G, Fayad Z, Stone PH, Waxman S, Raggi P, Madjid M, Zarrabi A, Burke A, Yuan C, Fitzgerald PJ, Siscovick DS, de Korte CL, Aikawa M, Juhani Airaksinen KE, Assmann G, Becker CR, Chesebro JH, Farb A, Galis ZS, Jackson C, Jang IK, Koenig W, Lodder RA, March K, Demirovic J, Navab M, Priori SG, Rekhter MD, Bahr R, Grundy SM, Mehran R, Colombo A, Boerwinkle E, Ballantyne C, Insull W Jr, Schwartz RS, Vogel R, Serruys PW, Hansson GK, Faxon DP, Kaul S, Drexler H, Greenland P, Muller JE, Virmani R, Ridker PM, Zipes DP, Shah PK, Willerson JT: From vulnerable plaque to vulnerable patient: a call for new defini- 
tions and risk assessment strategies: Part I. Circulation 2003 108(14): I664-1672.

39. Naghavi M, Libby P, Falk E, Casscells SW, Litovsky S, Rumberger J, Badimon J], Stefanadis C, Moreno P, Pasterkamp G, Fayad Z, Stone PH, Waxman S, Raggi P, Madjid M, Zarrabi A, Burke A, Yuan C, Fitzgerald PJ, Siscovick DS, de Korte CL, Aikawa M, Airaksinen KE, Assmann G, Becker CR, Chesebro JH, Farb A, Galis ZS, Jackson C, Jang IK, Koenig W, Lodder RA, March K, Demirovic J, Navab M, Priori SG, Rekhter MD, Bahr R, Grundy SM, Mehran R, Colombo A, Boerwinkle E, Ballantyne C, Insull W Jr, Schwartz RS, Vogel R, Serruys PW, Hansson GK, Faxon DP, Kaul S, Drexler H, Greenland P, Muller JE, Virman R, Ridker PM, Zipes DP, Shah PK, Willerson JT: From vulnerable plaque to vulnerable patient: a call for new definitions and risk assessment strategies: Part II. Circulation 2003, I08(I5): I772-I778.

40. Yuan C, Mitsumori LM, Beach KW, Maravilla KR: Carotid atherosclerotic plaque: noninvasive MR characterization and identification of vulnerable lesions. Radiology 200I, 22 I (2):285-299.

4I. Choudhury RP, Fuster V, Badimon JJ, Fisher EA, Fayad ZA: MRI and characterization of atherosclerotic plaque: emerging applications and molecular imaging. Arterioscler Thromb Vasc Biol 2002, 22(7): $1065-1074$

42. Fayad ZA: The assessment of the vulnerable atherosclerotic plaque using MR imaging: a brief review. Int J Cardiovasc Imaging 2001, 17(3): 165-177.

43. Fabiano S, Mancino S, Stefanini M, Chiocchi M, Mauriello A, Spagnoli L, Simonetti G: High-resolution multicontrast-weighted MR imaging from human carotid endarterectomy specimens to assess carotid plaque components. Eur Radiol 2008 , I 8( I 2):29|2-292I.

44. Saam T, Ferguson MS, Yarnykh VL, Takaya N, Xu D, Polissar NL, Hatsukami TS, Yuan C: Quantitative evaluation of carotid plaque composition by in vivo MRI. Arterioscler Thromb Vasc Biol 2005 , 25(I):234-239.

45. Cai J, Hatsukami TS, Ferguson MS, Kerwin WS, Saam T, Chu B, Takaya N, Polissar NL, Yuan C: In vivo quantitative measurement of intact fibrous cap and lipid-rich necrotic core size in atherosclerotic carotid plaque: comparison of high-resolution, contrast-enhanced magnetic resonance imaging and histology. Circulation 2005, I I 2(22):3437-3444.

46. Takaya N, Cai J, Ferguson MS, Yarnykh VL, Chu B, Saam T, Polissar NL, Sherwood ], Cury RC, Anders RJ, Broschat KO, Hinton D, Furie KL, Hatsukami TS, Yuan C: Intra- and interreader reproducibility of magnetic resonance imaging for quantifying the lipidrich necrotic core is improved with gadolinium contrast enhancement. J Magn Reson Imaging 2006, 24(I):203-2I0.

47. Kockx M, Cromheeke K, Knaapen M, Bosmans J, De Meyer G, Herman $\mathrm{A}$, Bult $\mathrm{H}$ : Phagocytosis and macrophage activation associated with hemorrhagic microvessels in human atherosclerosis. Arterioscler Thromb Vasc Biol 2003, 23(3):440-446.

48. Virmani R, Kolodgie F, Burke A, Finn A, Gold H, Tulenko T, Wrenn $S$, Narula J: Atherosclerotic plaque progression and vulnerability to rupture: angiogenesis as a source of intraplaque hemorrhage. Arterioscler Thromb Vasc Biol 2005, 25( I 0):2054-206 I.

49. Milei J, Parodi J, Ferreira M, Barrone A, Grana D, Matturri L: Atherosclerotic plaque rupture and intraplaque hemorrhage do not correlate with symptoms in carotid artery stenosis. J Vasc Surg 2003, 38(6): | 24|-| 247.

50. Singh N, Moody A, Gladstone D, Leung G, Ravikumar R, Zhan J, Maggisano R: Moderate Carotid Artery Stenosis: MR Imagingdepicted Intraplaque Hemorrhage Predicts Risk of Cerebrovascular Ischemic Events in Asymptomatic Men. Radiology 2009, 252(2):502-8

51. Chu B, Kampschulte A, Ferguson MS, Kerwin WS, Yarnykh VL, O'Brien KD, Polissar NL, Hatsukami TS, Yuan C: Hemorrhage in the atherosclerotic carotid plaque: a high-resolution MRI study. Stroke 2004, 35(5): 1079-1084.

52. Moody A, Murphy R, Morgan P, Martel A, Delay G, Allder S, MacSweeney S, Tennant W, Gladman J, Lowe J, Hunt B: Characterization of complicated carotid plaque with magnetic resonance direct thrombus imaging in patients with cerebral ischemia. Circulation 2003, 107(24):3047-3052.

53. Stary H: Natural history of calcium deposits in atherosclerosis progression and regression. Z Kardiol 2000, 89(Suppl 2):28-35.

54. Mintz G, Pichard A, Popma J, Kent K, Satler L, Bucher T, Leon M: Determinants and correlates of target lesion calcium in cor- onary artery disease: a clinical, angiographic and intravascular ultrasound study. J Am Coll Cardiol 1997, 29(2):268-274.

55. Raggi P, Callister T, Cooil B, He Z, Lippolis N, Russo D, Zelinger A, Mahmarian J: Identification of patients at increased risk of first unheralded acute myocardial infarction by electron-beam computed tomography. Circulation 2000, I0I(8):850-855.

56. Taylor A, Burke A, O'Malley P, Farb A, Malcom G, Smialek J, Virmani $\mathrm{R}$ : A comparison of the Framingham risk index, coronary artery calcification, and culprit plaque morphology in sudden cardiac death. Circulation 2000, I0 I (I I): 1243-1248.

57. Schmermund A, Erbel R: Unstable coronary plaque and its relation to coronary calcium. Circulation 2001, 104(14):1682-1687.

58. Huang $H$, Virmani R, Younis $H$, Burke A, Kamm R, Lee R: The impact of calcification on the biomechanical stability of atherosclerotic plaques. Circulation 200I, 103(8): I05I-1056.

59. Cheng G, Loree H, Kamm R, Fishbein M, Lee R: Distribution of circumferential stress in ruptured and stable atherosclerotic lesions. A structural analysis with histopathological correlation. Circulation 1993, 87(4): $1179-1187$.

60. Alderman E, Corley S, Fisher L, Chaitman B, Faxon D, Foster E, Killip $T$, Sosa J, Bourassa M: Five-year angiographic follow-up of factors associated with progression of coronary artery disease in the Coronary Artery Surgery Study (CASS). CASS Participating Investigators and Staff. J Am Coll Cardiol 1993, 22(4): I I I I-II54.

6I. Li Z, Howarth S, Tang T, Graves M, U-King-Im J, Gillard J: Does calcium deposition play a role in the stability of atheroma? Location may be the key. Cerebrovasc Dis 2007, 24(5):452-459.

62. Li Z, U-King-Im J, Tang T, Soh E, See T, Gillard J: Impact of calcification and intraluminal thrombus on the computed wall stresses of abdominal aortic aneurysm. J Vasc Surg 2008, 47(5):928-935

63. Merickel M, Carman C, Brookeman J, Mugler Jr, Brown M, Ayers C: Identification and 3-D quantification of atherosclerosis using magnetic resonance imaging. Comput Biol Med 1988, 18(2):89-102.

64. Kaufman L, Crooks L, Sheldon P, Rowan W, Miller T: Evaluation of NMR imaging for detection and quantification of obstructions in vessels. Invest Radiol I 7(6):554-560.

65. Libby $\mathrm{P}$, Ridker $\mathrm{P}$, Maseri A: Inflammation and atherosclerosis. Circulation 2002, 105(9): II35-II43.

66. Deguchi J, Aikawa M, Tung C, Aikawa E, Kim D, Ntziachristos V, Weissleder R, Libby P: Inflammation in atherosclerosis: visualizing matrix metalloproteinase action in macrophages in vivo. Circulation 2006, I | 4(I):55-62.

67. Jeziorska M, Woolley D: Local neovascularization and cellular composition within vulnerable regions of atherosclerotic plaques of human carotid arteries. I Pathol 1999 , 188(2): $189-196$.

68. Depré C, Havaux X, Wijns W: Neovascularization in human coronary atherosclerotic lesions. Cathet Cardiovasc Diagn 1996, 39(3):215-220.

69. Milei J, Parodi J, Alonso G, Barone A, Grana D, Matturri L: Carotid rupture and intraplaque hemorrhage: immunophenotype and role of cells involved. Am Heart J 1998, 136(6): 1096-I I05.

70. McCarthy M, Loftus I, Thompson M, Jones L, London N, Bell P, Naylor $A$, Brindle $N$ : Angiogenesis and the atherosclerotic carotid plaque: an association between symptomatology and plaque morphology. J Vasc Surg 1999, 30(2):26I-268.

71. Moreno P, Falk E, Palacios I, Newell J, Fuster V, Fallon J: Macrophage infiltration in acute coronary syndromes. Implications for plaque rupture. Circulation 1994, 90(2):775-778.

72. Moreno P, Purushothaman K, Fuster V, Echeverri D, Truszczynska $H$, Sharma S, Badimon J, O'Connor W: Plaque neovascularization is increased in ruptured atherosclerotic lesions of human aorta: implications for plaque vulnerability. Circulation 2004, I I 0( I4):2032-2038.

73. Mofidi R, Crotty T, McCarthy P, Sheehan S, Mehigan D, Keaveny T: Association between plaque instability, angiogenesis and symptomatic carotid occlusive disease. $\mathrm{Br}$ J Surg 200I, 88(7):945-950.

74. Jackson A, O'Connor J, Parker G, Jayson G: Imaging tumor vascular heterogeneity and angiogenesis using dynamic contrastenhanced magnetic resonance imaging. Clin Cancer Res 2007, I3( I 2):3449-3459. 
75. Patlak C, Blasberg R, Fenstermacher J: Graphical evaluation of blood-to-brain transfer constants from multiple-time uptake data. J Cereb Blood Flow Metab 1983, 3(I): I-7.

76. Kerwin W, O'Brien K, Ferguson M, Polissar N, Hatsukami T, Yuan C: Inflammation in carotid atherosclerotic plaque: a dynamic contrast-enhanced MR imaging study. Radiology 2006, 24I(2):459-468.

77. Kerwin W, Oikawa M, Yuan C, Jarvik G, Hatsukami T: MR imaging of adventitial vasa vasorum in carotid atherosclerosis. Magn Reson Med 2008, 59(3):507-5I4.

78. Kerwin W, Hooker A, Spilker M, Vicini P, Ferguson M, Hatsukami T, Yuan C: Quantitative magnetic resonance imaging analysis of neovasculature volume in carotid atherosclerotic plaque. Circulation 2003, 107(6):85 I-856

79. Trivedi R, Mallawarachi C, U-King-Im J, Graves M, Horsley J, Goddard M, Brown A, Wang L, Kirkpatrick P, Brown J, Gillard J: Identifying inflamed carotid plaques using in vivo USPIO-enhanced MR imaging to label plaque macrophages. Arterioscler Thromb Vasc Biol 2006, 26(7): I60I-I606.

80. Kooi M, Cappendijk V, Cleutjens K, Kessels A, Kitslaar P, Borgers M, Frederik P, Daemen M, van Engelshoven J: Accumulation of ultrasmall superparamagnetic particles of iron oxide in human atherosclerotic plaques can be detected by in vivo magnetic resonance imaging. Circulation 2003, I 07( I 9):2453-2458.

8I. Trivedi R, U-King-Im J, Graves M, Cross J, Horsley J, Goddard M, Skepper J, Quartey G, Warburton E, Joubert I, Wang L, Kirkpatrick $P$, Brown J, Gillard J: In vivo detection of macrophages in human carotid atheroma: temporal dependence of ultrasmall superparamagnetic particles of iron oxide-enhanced MRI. Stroke 2004, 35(7): I63 I-1635.

82. Tang T, Patterson A, Miller S, Graves M, Howarth S, U-King-Im J, Li Z, Sadat U, Young V, Walsh S, Boyle J, Gaunt M, Gillard J: Temporal dependence of in vivo USPIO-enhanced MRI signal changes in human carotid atheromatous plaques. Neuroradiology 2009, 5 I (7):457-465.

83. Moore A, Weissleder R, Bogdanov AJ: Uptake of dextran-coated monocrystalline iron oxides in tumor cells and macrophages. J Magn Reson Imaging 7(6): I | 40- I I 45.

84. Libby $P$, Geng $Y$, Aikawa M, Schoenbeck U, Mach F, Clinton S, Sukhova G, Lee R: Macrophages and atherosclerotic plaque stability. Curr Opin Lipidol 1996, 7(5):330-335.

85. Hansson G: Inflammation, atherosclerosis, and coronary artery disease. N Engl J Med 2005, 352(16): I685-1695.

86. Zhang S, Cai J, Luo Y, Han C, Polissar N, Hatsukami T, Yuan C: Measurement of carotid wall volume and maximum area with contrast-enhanced 3D MR imaging: initial observations. Radiology 2003, 228(I):200-205.

87. Saam T, Hatsukami TS, Yarnykh VL, Hayes CE, Underhill H, Chu B, Takaya N, Cai J, Kerwin WS, Xu D, Polissar NL, Neradilek B, Hamar WK, Maki J, Shaw DW, Buck RJ, Wyman B, Yuan C: Reader and platform reproducibility for quantitative assessment of carotid atherosclerotic plaque using I.5 T Siemens, Philips, and General Electric scanners. J Magn Reson Imaging 2007, 26(2):344-352.

88. Kang X, Polissar NL, Han C, Lin E, Yuan C: Analysis of the measurement precision of arterial lumen and wall areas using high-resolution MRI. Magn Reson Med 2000, 44(6):968-972.

89. Alizadeh Dehnavi R, Doornbos J, Tamsma JT, Stuber M, Putter H, Geest RJ van der, Lamb HJ, de Roos A: Assessment of the carotid artery by MRI at 3 T: a study on reproducibility. J Magn Reson Imaging 2007, 25(5): 1035-1043.

90. Vidal A, Bureau Y, Wade T, Spence JD, Rutt BK, Fenster A, Parraga $G$ : Scan-rescan and intra-observer variability of magnetic resonance imaging of carotid atherosclerosis at I.5 T and 3.0 T. Phys Med Biol 2008, 53(23):682 I-6835.

91. Underhill H, Kerwin W, Hatsukami T, Yuan C: Automated measurement of mean wall thickness in the common carotid artery by MRI: a comparison to intima-media thickness by Bmode ultrasound. J Magn Reson Imaging 2006, 24(2):379-387.

92. Saam T, Cai J, Ma L, Cai Y, Ferguson M, Polissar N, Hatsukami T, Yuan $C$ : Comparison of symptomatic and asymptomatic atherosclerotic carotid plaque features with in vivo MR imaging. Radiology 2006, 240(2):464-472.

93. Sadat U, Weerakkody R, Bowden D, Young V, Graves M, Li Z, Tang $T$, Gaunt $M$, Hayes P, Gillard J: Utility of high resolution MR imaging to assess carotid plaque morphology: A comparison of acute symptomatic, recently symptomatic and asymptomatic patients with carotid artery disease. Atherosclerosis 2009 , 207(2):434-9.

94. Yuan C, Zhang S, Polissar N, Echelard D, Ortiz G, Davis J, Ellington E, Ferguson M, Hatsukami T: Identification of fibrous cap rupture with magnetic resonance imaging is highly associated with recent transient ischemic attack or stroke. Circulation 2002, I05(2): $181-185$.

95. Murphy R, Moody A, Morgan P, Martel A, Delay G, Allder S, MacSweeney S, Tennant W, Gladman J, Lowe J, Hunt B: Prevalence of complicated carotid atheroma as detected by magnetic resonance direct thrombus imaging in patients with suspected carotid artery stenosis and previous acute cerebral ischemia. Circulation 2003, I07(24):3053-3058.

96. Howarth S, Tang T, Trivedi R, Weerakkody R, U-King-Im J, Gaunt M, Boyle J, Li Z, Miller S, Graves M, Gillard J: Utility of USPIOenhanced $M R$ imaging to identify inflammation and the fibrous cap: a comparison of symptomatic and asymptomatic individuals. Eur J Radiol 2009, 70(3):555-560.

97. Takaya N, Yuan C, Chu B, Saam T, Underhill H, Cai J, Tran N, Polissar N, Isaac C, Ferguson M, Garden G, Cramer S, Maravilla K, Hashimoto $B$, Hatsukami T: Association between carotid plaque characteristics and subsequent ischemic cerebrovascular events: a prospective assessment with MRI--initial results. Stroke 2006, 37(3):818-823.

98. Altaf N, Daniels L, Morgan P, Auer D, MacSweeney S, Moody A, Gladman J: Detection of intraplaque hemorrhage by magnetic resonance imaging in symptomatic patients with mild to moderate carotid stenosis predicts recurrent neurological events. J Vasc Surg 2008, 47(2):337-342.

99. Saam T, Cai J, Cai Y, An N, Kampschulte A, Xu D, Kerwin W, Takaya $\mathrm{N}$, Polissar N, Hatsukami T, Yuan C: Carotid plaque composition differs between ethno-racial groups: an MRI pilot study comparing mainland Chinese and American Caucasian patients. Arterioscler Thromb Vasc Biol 2005, 25(3):6 I I-6I6.

100. Saam T, Yuan C, Chu B, Takaya N, Underhill H, Cai J, Tran N, Polissar N, Neradilek B, Jarvik G, Isaac C, Garden G, Maravilla K, Hashimoto B, Hatsukami T: Predictors of carotid atherosclerotic plaque progression as measured by noninvasive magnetic resonance imaging. Atherosclerosis 2007, 194(2):e34-42.

10I. Prevention of cardiovascular events and death with pravastatin in patients with coronary heart disease and a broad range of initial cholesterol levels. The Long-Term Intervention with Pravastatin in Ischaemic Disease (LIPID) Study Group. N Engl ] Med 1998, 339( I 9): I349-1357.

102. Heart Protection Study Collaborative Group: MRC/BHF Heart Protection Study of cholesterol lowering with simvastatin in 20,536 high-risk individuals: a randomised placebo-controlled trial. Lancet 2002, 360(9326):7-22.

103. Amarenco P, Bogousslavsky J, Callahan A, Goldstein LB, Hennerici M, Rudolph AE, Sillesen H, Simunovic L, Szarek M, Welch KM, Zivin JA: High-dose atorvastatin after stroke or transient ischemic attack. N Engl J Med 2006, 355(6):549-559.

104. Corti R, Fuster V, Fayad ZA, Worthley SG, Helft G, Smith D, Weinberger J, Wentzel J, Mizsei G, Mercuri M, Badimon Jj: Lipid lowering by simvastatin induces regression of human atherosclerotic lesions: two years' follow-up by high-resolution noninvasive magnetic resonance imaging. Circulation 2002, I 06(23):2884-2887.

105. Corti R, Fuster V, Fayad ZA, Worthley SG, Helft G, Chaplin WF, Muntwyler J, Viles-Gonzalez JF, Weinberger J, Smith DA, Mizsei G, Badimon J]: Effects of aggressive versus conventional lipid-lowering therapy by simvastatin on human atherosclerotic lesions: a prospective, randomized, double-blind trial with high-resolution magnetic resonance imaging. J Am Coll Cardiol 2005, 46(I): $106-112$.

106. Underhill HR, Yuan C, Zhao XQ, Kraiss LW, Parker DL, Saam T, Chu B, Takaya N, Liu F, Polissar NL, Neradilek B, Raichlen JS, Cain VA, Waterton JC, Hamar W, Hatsukami TS: Effect of rosuvastatin therapy on carotid plaque morphology and composition in moderately hypercholesterolemic patients: a high-resolution magnetic resonance imaging trial. Am Heart J 2008 , I 55(3):e58|-588.

107. Zhao XQ, Dong L, Hatsukami TS, Phan BA, Chu B, Moore AB, Lane $T$, Neradilek B, Underhill HR, Yuan C: Magnetic resonance imaging of the plaque lipid depletion during lipid therapy: a pro- 
spective assessment of efficacy and time-course. A late breaking clinical trial report at ACC 2009, March 28-3I, Orlando 2009.

108. Underhill HR, Yuan C, Yarnykh VL, Chu B, Oikawa M, Polissar NL, Schwartz SM, Jarvik GP, Hatsukami TS: Arterial remodeling in the subclinical carotid artery: A natural history study. JACC Cardiovasc Imaging 2009 in press.

109. Dong L, Kerwin W, Chen HJ, Chu B, Underhill H, Phan BA, Neradilek MB, Moore A, Monic DA, Lee CD, Hatsukami T, Yuan C, Zhao XQ: Effect of Intensive Lipid Therapy on Atherosclerotic Plaque Inflammation: Evaluation Using Dynamic Contrastenhanced Magnetic Resonance Imaging (DCE-MRI) in Carotid Disease. AHA 2009, November 14-18, Orlando 2009 [httpirc.ahajournals.org/cgi/gca?allch $=\& S E A R C H I D=1 \& F U L$ LXT=abstract $+485 \&$ VOLUME $=120 \& \mid$ ISSUE $=18+$ Supple\&FIRSTINX $=$ $0 \&$ hits $=10 \&$ RESULTFORMAT $=\& \sigma c a=$ circula aha\%3B 20\%2FI8 MeetingAbstracts\%2FS342-c\&allchb=].

I 10. Tang T, Howarth S, Miller S, Graves M, Patterson A, U-King-Im J, Li Z, Walsh S, Brown A, Kirkpatrick P, Warburton E, Hayes P, Varty K, Boyle J, Gaunt M, Zalewski A, Gillard J: The ATHEROMA (Atorvastatin Therapy: Effects on Reduction of Macrophage Activity) Study. Evaluation using ultrasmall superparamagnetic iron oxide-enhanced magnetic resonance imaging in carotid disease. J Am Coll Cardiol 2009, 53(22):2039-2050.

III. Keenan N, Locca D, Varghese A, Roughton M, Gatehouse P, Hooper J, Firmin D, Pennell D: Magnetic resonance of carotid artery ageing in healthy subjects. Atherosclerosis 2009, 205(I): 168-I73.

I 12. O'Leary D, Polak J, Kronmal R, Manolio T, Burke G, Wolfson SJ: Carotid-artery intima and media thickness as a risk factor for myocardial infarction and stroke in older adults. Cardiovascular Health Study Collaborative Research Group. N Engl J Med 1999, 340(I): | 4-22.

1 13. Mani V, Muntner P, Gidding S, Aguiar S, El Aidi H, Weinshelbaum K, Taniguchi H, Geest R van der, Reiber J, Bansilal S, Farkouh M, Fuster V, Postley J, Woodward M, Fayad Z: Cardiovascular magnetic resonance parameters of atherosclerotic plaque burden improve discrimination of prior major adverse cardiovascular events. J Cardiovasc Magn Reson 2009, I I ( I): I0.

1 14. Flacke S, Fischer S, Scott M, Fuhrhop R, Allen J, McLean M, Winter P, Sicard G, Gaffney P, Wickline S, Lanza G: Novel MRI contrast agent for molecular imaging of fibrin: implications for detecting vulnerable plaques. Circulation 200I, I 04(I I): I280-1285.

I 15. Winter P, Morawski A, Caruthers S, Fuhrhop R, Zhang H, Williams T, Allen J, Lacy E, Robertson J, Lanza G, Wickline S: Molecular imaging of angiogenesis in early-stage atherosclerosis with alpha(v)beta3-integrin-targeted nanoparticles. Circulation 2003, I08( ( 8):2270-2274.

1 16. Lipinski M, Frias J, Amirbekian V, Briley-Saebo K, Mani V, Samber D, Abbate A, Aguinaldo J, Massey D, Fuster V, Vetrovec G, Fayad Z: Macrophage-specific lipid-based nanoparticles improve cardiac magnetic resonance detection and characterization of human atherosclerosis. JACC Cardiovasc Imaging 2009, 2(5):637-647.

117. Beilvert A, Cormode D, Chaubet F, Briley-Saebo K, Mani V, Mulder W, Vucic E, Toussaint J, Letourneur D, Fayad Z: Tyrosine polyethylene glycol (PEG)-micelle magnetic resonance contrast agent for the detection of lipid rich areas in atherosclerotic plaque. Magn Reson Med 2009, 62(5): I I95-I20I.

I 18. Kramer H, Michaely H, Reiser M, Schoenberg S: Peripheral magnetic resonance angiography at 3.0 T. Top Magn Reson Imaging 2007, I 8(2):345-138.

119. Momiyama $Y$, Fayad Z: Aortic plaque imaging and monitoring atherosclerotic plaque interventions. Top Magn Reson Imaging 2007, I 8(5):349-355.

120. Botnar R, Stuber M, Kissinger K, Kim W, Spuentrup E, Manning W: Noninvasive coronary vessel wall and plaque imaging with magnetic resonance imaging. Circulation 2000, I 02(2I):2582-2587.

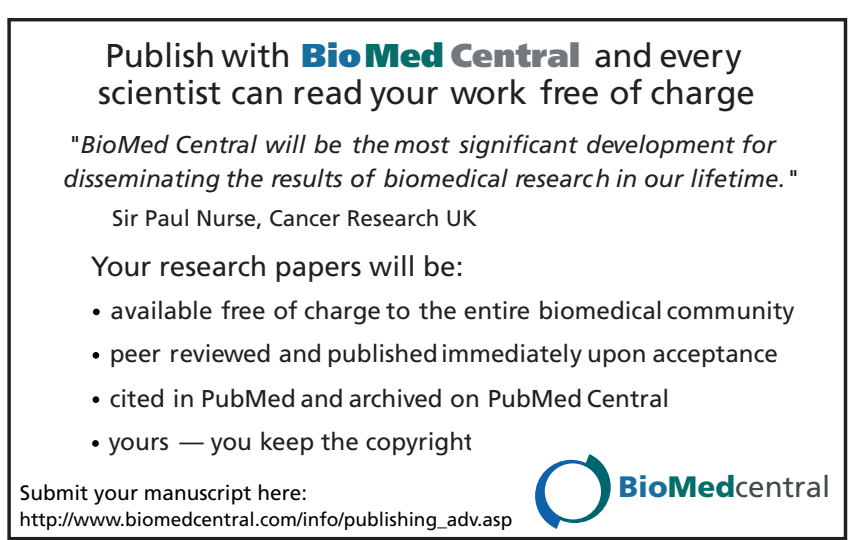

